\title{
Stress Response to Propofol versus Isoflurane Anesthesia in Patients Undergoing Gastric Surgery
}

\author{
Yan Wu1, Le Zhang2, Gang Yin1, Yishu Liu1 and Li Chen1
}

\begin{abstract}
Objective: To compare the effects of propofol and isoflurane anesthesia on cortisol, insulin, and blood glucose levels surrounding operation period in patients undergoing gastric surgery.

Study Design: An experimental study.

Place and Duration of Study: The Department of Anesthesiology, Hubei Cancer Hospital, Wuhan, China, from October 2016 to January 2018.

Methodology: A total of 86 patients, undergoing for gastric surgery, were divided randomly into propofol group and isoflurane group with 43 cases in each group. Propofol group used total intravenous anesthesia of propofol and isoflurane group used total intravenous anesthesia of isoflurane. Operation time, serum cortisol, insulin, and blood glucose levels were compared at 5 minutes before anesthesia $\left(T_{1}\right), 1$-hour after anesthesia $\left(T_{2}\right), 1$-hour after the operation $\left(T_{3}\right)$ and 48 hours after operation $\left(T_{4}\right)$.

Results: There was no significant difference in operation time between two groups $(p=0.642)$. At $T_{1}$, there were no significant differences in level of serum cortisol, blood glucose, and insulin between two groups $(p=0.644,0.534$ and 0.913 , respectively). At $T_{2}, T_{3}, T_{4}$, serum cortisol and blood glucose in propofol group were having less increasing pattern, and were lower than those in isoflurane group (all $p<0.001$ ), while insulin levels in propofol group were higher than those in isoflurane group (all $p<0.001)$.

Conclusion: Propofol can promote the secretion of insulin during radical gastrectomy, and inhibit the excessive secretion of cortisol and hyperglycemia. Either propofol or sevoflurane, to certain extent, can affect patients' stress response when they are applied in patients undergoing for gastric surgery. However, the influence of propofol on stress response is relatively smaller.
\end{abstract}

Key Words: Propofol, Isoflurane, Gastric surgery, Cortisol, Insulin, Blood glucose.

\section{INTRODUCTION}

Surgery is the principal treatment of gastric cancer. However, under the stress effect of operation, the immune system of tumor patients is vulnerable to serious effects, which leads to a decrease in patients' own immunity, and influence the postoperative survival rate. ${ }^{1}$ Upper abdominal and chest surgery often lead to hyperglycemia, insulin resistance, accompanied by increased levels of stress hormones such as cortisol and catecholamine. ${ }^{2}$ Postoperative insulin resistance (IR) refers to a patient who is in a special metabolic state similar to type II diabetes after the operation; and whose biological response to insulin is weaker than normal. ${ }^{3}$ Insulin resistance is very common after operation, but severe insulin resistance changes the body supply from

\footnotetext{
1 Department of Anesthesiology, Hubei Cancer Hospital, Wuhan, 430079 China

2 Department of Anesthesiology, The First Affiliated Hospital of Zhengzhou University, Zhengzhou, 450052 China

Correspondence: Dr. Li Chen, Department of Anesthesiology, Hubei Cancer Hospital, Wuhan, 430079 China

E-mail: ehdhsamtfsp4@163.com
}

Received: April 10, 2018; Accepted: October 09, 2018 sugar to fat, which affects the postoperative recovery of patient. ${ }^{4}$ Postoperative insulin resistance is linked to the degree of surgical trauma and the intensity of stimulation. It is part of the indicators to reflect the degree of surgical trauma. 5 In recent years, more and more attention is drawn to the changes in insulin secretion and glucose metabolism disorders induced by stress response, as well as the specific actions of glucocorticoid in stress response. 6

Propofol is a general anesthetic widely used in clinical practice. One study showed that the influence of propofol on cognitive function is relatively smaller, comparing with sevoflurane. ${ }^{7}$ Schoen et al. revealed that strong fastest recovery of cognitive performance appears after propofol anesthesia, then follows sevoflurane based anesthesia, and after that isoflurane anesthesia. ${ }^{8}$ But there are few reports about its effect on preoperative glucose metabolism and cortisol in patients with radical operation for carcinoma of stomach. Isoflurane is an important inhalational anaesthetic agent available in the market. 9

The objective of this study was to compare the effects of propofol and isoflurane anesthesia on cortisol, insulin, and blood glucose levels surrounding operation period in patients undergoing gastric surgery. 


\section{METHODOLOGY}

This study was conducted in the Department of Anesthesiology, Hubei Cancer Hospital, Wuhan, China, from October 2016 to January 2018. Selected were patients undergoing gastric surgery as study subjects. The study was approved by the Hospital Ethical and Research Committee, and all the patients signed the informed consents. Inclusion criteria were patients who were diagnosed and confirmed as gastric carcinoma by clinical and pathological examination; did not use preoperative radiotherapy, chemotherapy or immunosuppressive drugs; non-diabetic and hypertensive patients; having no history of analgesics, sedatives or hormone drugs. Exclusion criteria were patients with gastric diseases such as gastric polyps, superficial gastritis, hypertrophic gastritis, and gastric ulcers; associated with malignant neoplasms or severe heart, liver and kidney dysfunction. A total of 86 patients were randomly divided into propofol group and isoflurane group with 43 cases in each group.

All patients were given 1 2 mg of estazolam tablet 2 hours before operation. Continuous monitoring of the patients' blood pressure (BP), heart rate (HR), electrocardiogram (ECG), oxygen saturation $\left(\mathrm{SpO}_{2}\right)$ and end-expiratory carbon dioxide partial pressure $\left(\mathrm{ETCO}_{2}\right)$ were done after entering the operating room with a multifunctional monitor. The patient underwent a right internal jugular vein puncture under local anesthesia and a double vena cava catheter was placed to obtain blood samples, anesthesia induction and maintenance, and intraoperative infusion. Both groups were treated with the same method for general anesthesia induction. Patients were given oxygen for 2-4 minutes, slowly intravenously injected midazolam $0.1-0.15 \mathrm{mg} / \mathrm{Kg}$, injected $0.1 \mathrm{mg} / \mathrm{kg}$ of vecuronium after falling asleep, assisted, controlled breathing, followed by fentanyl $4-5 \mu \mathrm{g} / \mathrm{kg}$, tracheal intubation after four minutes, mechanical ventilation by anaesthesia machine, with breathing frequency at 10-14 times/minutes, tidal volume of $8-10 \mathrm{ml} / \mathrm{kg}$, and oxygen flow at $2.0 \mathrm{~L} / \mathrm{min}$. Patients in propofol group accepted continuous infusion of propofol at a speed of $4-6 \mathrm{mg} / \mathrm{kg}$ per hour by microinfusion pump; the patients continued to inhale $1.5-2.0 \%$ isoflurane, all patients were given intravenously fentanyl $0.05-0.1 \mathrm{mg}$ and vecuronium $2-4$ $\mathrm{mg}$ in accordance with changes in HR, BP and muscle relaxation in the operation period, maintaining the $\mathrm{SpO}_{2}$ at $100 \%$ and $\mathrm{ETCO}_{2}$ between $30-35 \mathrm{mmHg}$. Ten to fifteen minutes before the end of operation, $1-2 \mathrm{mg}$ of neostigmine and $0.5 \mathrm{mg}$ of atropine were given to antagonise the residual effect of muscle relaxant. Mechanical ventilation was stopped after the patients had recovered spontaneous respiration, and the respiratory secretion and the tracheal catheter were removed when tidal volume met the standard, swallowing reflex was recovered, and conscious awareness and $\mathrm{SpO}_{2}$ exceeding $98 \%$ in natural state. Intravenous analgesia pump was connected and fentanyl for patient-controlled analgesia was used at the end of operation. Since then, the patient was sent back to the monitor unit.

Operation time, serum cortisol and insulin, and blood glucose level were compared at five minutes before anesthesia $\left(T_{1}\right)$, 1-hour after anesthesia $\left(T_{2}\right)$, 1-hour after the operation $\left(\mathrm{T}_{3}\right)$ and 48 hours after operation $\left(\mathrm{T}_{4}\right)$. Data were analysed and processed by SPSS version 22 . The measurement data were expressed by mean \pm standard deviation, and the two groups were compared by independent sample t-test, and $p<0.05$, the difference, was statistically significant.

\section{RESULTS}

There were 46 (53.49\%) males and 40 (46.51\%) females. They were aged 48-73 years, average age being $56.32 \pm 2.75$ years; weighting 49-66 kgs, average weight being $57.15 \pm 1.92 \mathrm{kgs}$. Thirty-four $(39.53 \%)$ cases belonged to ASA I, and $52(60.47 \%)$ cases to ASA II.

Operation time in propofol group was $136.83 \pm 17.32$ minutes,and operation time in isoflurane group was $138.51 \pm 16.07$ minutes. There was no significant difference in operation time between two groups $(p=0.642)$. With prolongation of the time of anesthesia and operation, the serum cortisol content in both groups increased gradually, and finally reached its peak at $T_{3}$. Afterwards, it decreased gradually. At $T_{1}$, there were no significant differences in serum cortisol levels between two groups ( $p=0.644)$. At $T_{2}, T_{3}$, and $T_{4}$, serum cortisol in the propofol group was increased less and was lower than that in isoflurane group (all $p<0.001$, Table I).

Table I: Comparison of the cortisol levels between the two groups in operation period $(\mathrm{ng} / \mathrm{mL})$.

\begin{tabular}{|c|c|c|c|c|c|c|c|c|c|}
\hline \multirow[t]{2}{*}{ Groups } & \multirow[t]{2}{*}{$\mathrm{n}$} & \multicolumn{2}{|l|}{$\mathrm{T}_{1}$} & \multicolumn{2}{|c|}{$\mathrm{T}_{2}$} & \multicolumn{2}{|c|}{$\mathrm{T}_{3}$} & \multicolumn{2}{|c|}{$\mathrm{T}_{4}$} \\
\hline & & Mean \pm SD & $\mathrm{p}$-value & Mean \pm SD & $p$-value & Mean \pm SD & $\mathrm{p}$-value & Mean \pm SD & $\mathrm{p}$-value \\
\hline Propofol group & 43 & $312.54 \pm 19.52$ & 0.644 & $390.42 \pm 39.04$ & $<0.001$ & $462.95 \pm 58.55$ & $<0.001$ & $303.45 \pm 34.16$ & $<0.001$ \\
\hline Isoflurane group & 43 & $314.75 \pm 24.40$ & & $453.48 \pm 48.80$ & & $531.14 \pm 63.43$ & & $398.86 \pm 57.74$ & \\
\hline
\end{tabular}

Table II: Comparison of the level of blood glucose in operation period between the two groups (mmol/L).

\begin{tabular}{|c|c|c|c|c|c|c|c|c|c|}
\hline \multirow[t]{2}{*}{ Groups } & \multirow[t]{2}{*}{$\mathrm{n}$} & \multicolumn{2}{|c|}{$\mathrm{T}_{1}$} & \multicolumn{2}{|c|}{$\mathrm{T}_{2}$} & \multicolumn{2}{|c|}{$\mathrm{T}_{3}$} & \multicolumn{2}{|c|}{$\mathrm{T}_{4}$} \\
\hline & & Mean \pm SD & $p$-value & Mean \pm SD & $\mathrm{p}$-value & Mean \pm SD & $p$-value & Mean \pm SD & $\mathrm{p}$-value \\
\hline Propofol group & 43 & $4.74 \pm 0.34$ & 0.534 & $6.03 \pm 0.39$ & $<0.001$ & $7.45 \pm 0.15$ & $<0.001$ & $4.78 \pm 0.46$ & $<0.001$ \\
\hline Isoflurane group & 43 & $4.78 \pm 0.24$ & & $8.25 \pm 0.40$ & & $9.39 \pm 0.35$ & & $6.01 \pm 0.49$ & \\
\hline
\end{tabular}


Table III: Comparison of the level of insulin in operation period between the two groups $(\mathrm{IU} / \mathrm{mL})$.

\begin{tabular}{|c|c|c|c|c|c|c|c|c|c|}
\hline \multirow[t]{2}{*}{ Groups } & \multirow[t]{2}{*}{$\mathrm{n}$} & \multicolumn{2}{|c|}{$\mathrm{T}_{1}$} & \multicolumn{2}{|c|}{$T_{2}$} & \multicolumn{2}{|c|}{$T_{3}$} & \multicolumn{2}{|c|}{$\mathrm{T}_{4}$} \\
\hline & & Mean $\pm S D$ & p-value & Mean $\pm S D$ & $p$-value & Mean \pm SD & $p$-value & Mean $\pm S D$ & $p$-value \\
\hline Propofol group & 43 & $11.18 \pm 0.68$ & 0.913 & $8.87 \pm 0.59$ & $<0.001$ & $7.01 \pm 0.98$ & $<0.001$ & $10.74 \pm 0.51$ & $<0.001$ \\
\hline Isoflurane group & 43 & $11.20 \pm 0.45$ & & $7.43 \pm 0.58$ & & $5.65 \pm 0.78$ & & $9.52 \pm 0.36$ & \\
\hline
\end{tabular}

For patients in both groups, with the prolongation of anesthesia and surgery, the blood glucose gradually increased and the insulin gradually decreased. At $T_{1}$, there were no significant difference in the level of blood glucose and insulin between two groups ( $p=0.534$ and 0.913 , respectively). At $T_{2}, T_{3}$, and $T_{4}$, level of blood glucose in propofol group was less rise and the level was lower than that in isoflurane group (all $p<0.001$ ); insulin levels in propofol group were higher than those in isoflurane group (all $p<0.001$, Table II and Table III).

\section{DISCUSSION}

In clinic, surgery anesthesia and stimulation of extubation of tracheal catheter and sucking sputum of oropharynx can increase the secretion of aldosterone, angiotensin, renin, cortisol, catecholamine and so on. It is possible to cause stress reaction in patients, which is unfavorable to the operation when the level of above substances is exceeded. $10 \mathrm{~A}$ study showed that the surgical stress has been present in gastric carcinoma surgery. ${ }^{11}$ Moriwaki et al. indicated that surgical stress associated with palliative resection for patients with incurable gastric cancer with distant metastasis may shorten their survival. 12

Propofol and isoflurane are common anesthetic agents. ${ }^{13}$ Propofol has obvious lipophilic properties. It can rapidly reach the central nervous system and the surrounding tissue ion channels and carry out rapid distribution through the vein into the blood and it can reach the high peak of blood concentration in two minutes. Its pharmacokinetics is relatively stable; the concentration of blood drops rapidly and wakes up quickly after stopping the administration. ${ }^{14}$ Some studies have reported that the use of propofol significantly reduces postoperative pain after an open radical gastrectomy procedure. ${ }^{15}$ Isoflurane is an inhaled anesthetic. This kind of drug quickly enters the blood to achieve balance after inhalation, and has no inhibition on respiration. Most of the drugs pass through the lungs, so patients can wake up faster. ${ }^{16}$

According to a study, surgery under isoflurane anesthesia induces acute neuroinflammation in the early postoperative period along with related trace and context memory dysfunction. ${ }^{17}$

Cortisol is a type of glucocorticoid secreted by the upper cortical tract of kidney. It is a significant index to evaluate the severity of stress response and has high sensitivity. Both external and internal adverse stimuli can lead to an increase in serum cortisol levels, which are closely linked to stress response, duration and intensity of stimulation. The longer of the stimulus duration, the greater of the intensity, and the higher of the serum cortisol level, the most acute of the body stress response. 18,19 This research has found that with the prolongation of anesthesia and operation time, the serum cortisol content in both groups gradually increased, reached its peak at $T_{3}$ time point, and then decreased gradually. It suggests that under the stimulation of operation and anesthesia, the patients in the two groups have an obvious stress response. This is due to the fact that during the course of the operation, the hypothalamus appears the stress reaction to cause the adrenal hormone concentration to rise, the glucocorticoid is secreted in large quantities, thus promotes the liver glycogen to decompose, the glycometabolism increases. ${ }^{20}$ At $T_{1}$, there is no significant difference between the two groups of serum cortisol levels. At $T_{2}, T_{3}, T_{4}$, serum cortisol in the propofol group having less increasing pattern, and was lower than that in isoflurane group. It is suggested that propofol can effectively relieve stress response in patients, and its mechanism may be propofol acting on the c-fos gene of the central nervous system and inhibiting its expression, thereby inhibiting the activity of the hypothalamus pituitary adrenal axis, and relieving the stress response.

The concentration of blood glucose is mainly regulated by glucose secreted by $\alpha$ cells and insulin secreted by $\beta$ cells. However, the glucose can increase the level of blood glucose while insulin can increase glycogen synthesis and storage by increasing glucose-to-cells transport, and inhibit glycogen decomposition and gluconeogenesis, thus reducing blood glucose level. ${ }^{21}$ Besides, the blood glucose is used as the effect of surgical stress response, which shows indirectly the intensity of stress response.22 The authors found that there was increasing pattern in both propofol group and isoflurane group for blood glucose, but it was less than isoflurane. Insulin is generated from the schizolytic molecule of proinsulin, which is used for reflecting $\beta$ cells secretion function of organism. The authors found that, compared with isoflurane, the propofol will significantly improve the secretion function of islet $\beta$ cells for patients during operation, while increasing insulin secretion and inhibited hyperglycemia during the operation.Thus, it can be seen that stress response to surgery will be less in propofol group as compared to isoflurane group. 


\section{CONCLUSION}

Propofol can promote the secretion of insulin during radical gastrectomy, and inhibit the excessive secretion of cortisol and hyperglycemia. Either propofol or sevoflurane, to certain extent, can affect patients' stress response when they are applied in patients undergoing gastric surgery. However, the influence of propofol on stress response is relatively smaller.

\section{REFERENCES}

1. Surinenaite B, Prasmickiene G, Milasiene V, Stratilatovas E, Didziapetriene $\mathrm{J}$. The influence of surgical treatment and red blood cell transfusion on changes in antioxidative and immune system parameters in colorectal cancer patients. Medicina (Kaunas) 2009; 45:785-91.

2. Elsharydah A, Williams TM, Rosero EB, Joshi GP. Epidural analgesia does not increase the rate of inpatient falls after major upper abdominal and thoracic surgery: a retrospective case-control study. Can J Anaesth 2016; 63:544-51.

3. Rizzello M, Abbatini F, Casella G, Alessandri G, Fantini A, Leonetti $F$, et al. Early postoperative insulin-resistance changes after sleeve gastrectomy. Obes Surg 2010; 20:50-5.

4. Hideki T, Toshio S, Hisae F, Osami T, Tsutomu H, Haruhiko C, et al. The effect of intraoperative use of high-dose remifentanil on postoperative insulin resistance and muscle protein catabolism: a randomized controlled study. Int J Med Sci 2013; 10:1099-107.

5. Radunovic M, Radunovic M, Radunovic M, Lazovic R, Panic N, Bulajiic M. Biohumoral and endocrine parameters in assessment of surgical trauma in open and laparoscopic cholecystectomy. Vojnosanit Pregl 2013; 70:555-60.

6. Nikolic I, Vujicic M, Saksida T, Berki T, Stosic-Grujicic S, Stojanovic I. The role of endogenous glucocorticoids in glucose metabolism and immune status of MIF-deficient mice. Eur $\mathrm{J}$ Pharmacol 2013; 714:498-506.

7. Yu W. Anesthesia with propofol and sevoflurane on postoperative cognitive function of elderly patients undergoing general thoracic surgery. Pak J Pharm Sci 2017; 30:1107-10.

8. Schoen J, Husemann L, Tiemeyer C, Lueloh A, Sedemundadib B, Berger $\mathrm{KU}$, et al. Cognitive function after sevoflurane- vs propofol-based anaesthesia for on-pump cardiac surgery: A randomized controlled trial. Brit J Anaesth 2011; 106:840-50.

9. Dohoo SE. Isoflurane as an inhalational anesthetic agent in clinical practice. Can Vet J 1990; 31:847-50.

10. Zhao J, Mo H. The impact of different anesthesia methods on stress reaction and immune function of the patients with gastric cancer during perioperative period. J Med Assoc Thai 2015; 98:568-73.
11. Haga Y, Wada Y, Takeuchi H, Ikejiri K, Ikenaga M, Kimura O. Evaluation of modified estimation of physiologic ability and surgical stress in gastric carcinoma surgery. Gastric Cancer 2012; 15:7-14.

12. Moriwaki $Y$, Kunisaki C, Kobayashi S, Harada H, Imai S, Kasaoka C. Does the surgical stress associated with palliative resection for patients with incurable gastric cancer with distant metastasis shorten their survival? Hepatogastroenterology 2004; 51:872-5.

13. Sheybani S, Attar AS, Golshan S, Sheibani S, Rajabian M. Effect of propofol and isoflurane on gas exchange parameters following one-lung ventilation in thoracic surgery: A doubleblinded randomized controlled clinical trial. Electron Physician 2018; 10:6346-53.

14. Kreienbühl L, Elia N, Pfeil-Beun E, Walder B, Tramèr MR. Patient-controlled versus clinician-controlled sedation with propofol: systematic review and meta-analysis with trial sequential analyses. Anesth Analg 2018; 127:873-80.

15. Ji FH, Wang D, Zhang J, Liu HY, Peng K. Effects of propofol anesthesia versus sevoflurane anesthesia on postoperative pain after radical gastrectomy: a randomized controlled trial. $J$ Pain Res 2018; 11:1247-54.

16. Sanders RD, Xu J, Shu Y, Januszewski A, Halder S, Fidalgo A, et al. Dexmedetomidine attenuates isoflurane-induced neurocognitive impairment in neonatal rats. Anesthesiology 2009; 110:1077-85.

17. Kawano T, Yamanaka D, Aoyama B, Tateiwa H, ShigematsuLocatelli $M$, Nishigaki $A$, et al. Involvement of acute neuroinflammation in postoperative delirium-like cognitive deficits in rats. J Anesth 2018; 32:506-17.

18. Roelfsema F, Aoun P, Veldhuis JD. Pulsatile cortisol feedback on acth secretion is mediated by the glucocorticoid receptor and modulated by gender. J Clin Endocrinol Metab 2016; 101:4094-102.

19. Ceccato F, Barbot M, Lizzul L, Selmin E, Saller A, Albiger N, et al. Decrease of salivary cortisol levels after glucocorticoid dose reduction in patients with adrenal insufficiency: A prospective proof-of-concept study. Clin Endocrinol (Oxf) 2018; 88:201-8.

20. Salman TM, Alagbonsi IA, Biliaminu SA, Ayandele OA, Oladejo OK, Adeosun OA. Blood glucose-lowering effect of telfairia occidentalis: a preliminary study on the underlying mechanism and responses. Niger Soc Exp Biol 2014; 25:133-9.

21. Dupont J, Scaramuzzi RJ. Insulin signalling and glucose transport in the ovary and ovarian function during the ovarian cycle. Biochem J 2016; 473:1483-501.

22. Chaki T, Nawa Y, Tamashiro K, Mizuno E, Hirata N, Yamakage M. Remifentanil prevents increases of blood glucose and lactate levels during cardiopulmonary bypass in pediatric cardiac surgery. Ann Card Anaesth 2017; 20:33-7. 